Research Article

\title{
Entomological Survey of Vectors of Scrub Typhus in Haulawng, Lunglei District, Mizoram, India
}

\author{
Lalthazuali', Abhay Kumar Sharma ${ }^{2}$, TG Thomas ${ }^{3}, \underline{\text { Sweta Bhan }}^{4}$, Amarpal Singh Bhadauriya $^{5}$, \\ Pankaj U Ramteke ${ }^{6}$, Rina Kumawat ${ }^{7}$, Ram Singh ${ }^{8}$ \\ 1,2,3,4,5,6,7,8 Centre for Medical Entomology \& Vector Management, National Centre for Disease Control, 22-Sham Nath Marg, \\ Delh, India. \\ DOI: https://doi.org/10.24321/0019.5138.202013
}

\section{I $\quad \mathbf{N} \quad \mathbf{F} \quad \mathbf{O}$}

\author{
Corresponding Author: \\ Lalthazuali, Centre for Medical Entomology \& \\ Vector Management, National Centre for Disease \\ Control, 22-Sham Nath Marg, Delhi, India. \\ E-mail Id: \\ zualteikawilam26@gmail.com \\ Orcid Id: \\ https://orcid.org/0000-0002-4656-0033 \\ How to cite this article: \\ Lalthazuali, Sharma AK, Thomas TG, Bhan S, \\ Bhadauriya AS, Ramteke PU. Entomological \\ Survey of Vectors of Scrub Typhus in Haulawng, \\ Lunglei District, Mizoram, India. J Commun Dis \\ 2020; 52(2): 69-73. \\ Date of Submission: 2020-06-02 \\ Date of Acceptance: 2020-06-17
}

\section{$\begin{array}{llllllllllllll}\mathbf{A} & \mathbf{B} & \mathbf{S} & \mathbf{T} & \mathbf{R} & \mathbf{A} & \mathbf{C} & \mathbf{T}\end{array}$}

A study on the vector prevalence of Scrub typhus was undertaken in the Scrub typhus affected areas in Lunglei district, Mizoram. Rodents were trapped using live traps and examined for ectoparasites and serological test for scrub typhus antibodies was also done. Results on the vectors of the Scrub typhus revealed the presence of the vector mite Leptotrombidium deliense on the rats in 3 localities of Haulawng village. Chigger index was found to be 12.33 , which is above the critical index of 0.69 per rodent. Chigger infestation rate was 18.5. The chigger infestation was found mainly on Rattus rattus. Detection of Orientia (Scrub typhus) 1:20 and 1:80 has been calculated by Weil Felix OXK antigen. Observation of the vector of Scrub typhus warrants regular surveillance in these areas to prevent any impending outbreak.

Keywords: Scrub Typhus, Tromboculid mites ( Chigger), Transtadial and Transovarian Transmission, Re-emerging

\section{Introduction}

Ecto-parasites constitutes a major group of vectors, transmitting the causative agents of Scrub typhus (mite borne) diseases, in addition to few other diseases of local and focal importance. ${ }^{1}$ Scrub typhus is an acute, febrile disease caused by infection with Orientia tsutsugamushi (Family: Rickettsiaceae). It is an obligate intracellular Gram negative bacterium, transmitted among small animals and to humans by some species of larval trombiculid mites (chiggers). Mites carry the bacterium from larval stages to adults and to their progenies through transtadial and transovarial transmission. ${ }^{2}$ It is the most common re-emerging Rickettsial infection in India and many other South East Asian countries. In fact, Scrub typhus is confined geographically to the Asia Pacific region, a billion people are at risk and nearly a million cases are reported every year. ${ }^{2}$ Scrub typhus is a public health problem in Mizoram. Enormous numbers of cases were reported from Aizawl East district since 2012 till date (540) and 16 deaths followed by Lunglei district (302) and Aizawl West (297). Districts like Champhai, Serchhip and State Referral hospital also has more number of cases. Other districts were also infected from Scrub typhus. Cases of Scrub typhus was witnessed recently in Phullen village of Aizawl district, resulting in the death of one person while affecting 89 others in Phullen and its neighboring villages like Luangpawn, Thanglailung and Zawngin. In Haulawng and its neighbouring villages, Lunglei district, number of Scrub typhus cases has gone up to 195 with no death till first week of February 2018. In Mizoram over more than 1,000 people were infected with scrub typhus of which 38 
people have died since 2012. Prior to year 2012, no data was available. Field study was not undertaken in affected areas of these locations, for vector surveillance of Scrub typhus. The Integrated Disease Surveillance Programme (IDSP) Mizoram initiated the collection and recording of scrub typhus disease data from District hospitals and Private hospitals within the state from January 2012. The cases and deaths in different districts are regularly occurring in Mizoram. As recorded by IDSP, Mizoram, there has been outbreaks of the disease from various parts of the state during the past few years. The first outbreak of the disease was recorded from Falkawn Referral hospital area during the month of October 2015. Sixty two (62) cases were recorded with 1 death case during this outbreak. The second outbreak was recorded from Khawbung PHC area, Champhai district during the month of December 2016. 47 seropositive cases were recorded with no death case from this outbreak. The third outbreak was recorded from Phullen PHC area under Aizawl East district during the month of December 2017. 90 people were affected by the disease with 1 death case from the outbreak. The fourth outbreak was recorded from Haulawng PHC area under Lunglei district during the month of January 2018. 199 positive cases were recorded with no death case. Year and month wise occurrence of Scrub typhus in Mizoram is given in Table 1.

In order to ascertain the prevalence of rodent-vector mite association a team of experts from the National Centre for Diseases Control (NCDC) visited Scrub typhus affected areas of Lunglei district in Mizoram during $7^{\text {th }}$ February- $14^{\text {th }}$ February 2018 as requested by Health and Family Welfare Department, Government of Mizoram due to successive outbreaks at Phullen PHC area during December 2017 and Haulawng PHC area during January 2018, with the following objectives:

- To undertake joint rodent/ vector mite surveillance in the areas reported scrub typhus cases earlier.

- To detect the evidence of Orientia/ plague antibodies in rodent population if any.

The findings of the study are presented in this communication.

\section{Methodology}

\section{Geographical Information on Study Area}

Mizoram is a mountainous region which occupies an area of great strategic importance in the north-eastern corner of India. The state of Mizoram covers an area of 21,087 sq km. It is rich in natural beauty and makes for a popular tourist destination. Mizoram shares its geographical boundaries with Assam, Manipur and Tripura that extends over $123 \mathrm{~km}$, $95 \mathrm{~km}$ and $66 \mathrm{~km}$ respectively. It has a total of 630 miles of international border with Myanmar and Bangladesh. Mizoram has a pleasant climate. It is generally cool in summer and not very cold in winter. During winter, the temperature varies from $11^{\circ} \mathrm{C}$ to $21^{\circ} \mathrm{C}$ and in summer it varies between $20^{\circ} \mathrm{C}$ to $29^{\circ} \mathrm{C}$. The entire are is under the direct influence of the monsoon. It rains heavily from May to September and the average rainfall is $254 \mathrm{~cm}$, per annum. The average rainfall in Aizawl is $208 \mathrm{~cm}$, and Lunglei has $350 \mathrm{~cm}$. Lunglei district is one of the eight districts of Mizoram state in India. As of 2011 it is the second most populous district in the state, after Aizawl. The district is bounded on the north by Mamit and Aizawl districts, on the west by Bangladesh, on the south by Lawngtlai district, on the southeast by Saiha district, on the east by Myanmar and on the northeast by Serchhip District. It is also the largest district in Mizoram with an area of $4,572 \mathrm{~km}^{2}(1,765 \mathrm{sq} \mathrm{mi})$.

Table I.The District wise number of Scrub typhus cases \& deaths in Mizoram reported through IDSP (20I2-20I8)

\begin{tabular}{|c|c|c|c|c|c|c|c|c|c|c|c|c|c|c|c|c|}
\hline \multirow{2}{*}{ Name of District } & \multicolumn{2}{|c|}{2012} & \multicolumn{2}{|c|}{2013} & \multicolumn{2}{|c|}{2014} & \multicolumn{2}{|c|}{2015} & \multicolumn{2}{|c|}{2016} & \multicolumn{2}{|c|}{2017} & \multicolumn{2}{|c|}{2018} & \multicolumn{2}{|c|}{ Total } \\
\hline & C & D & C & D & C & D & C & D & $\mathrm{C}$ & D & C & D & C & D & C & D \\
\hline Aizawl East & 98 & 5 & 28 & 2 & 85 & 2 & 34 & 4 & 7 & 0 & 101 & 1 & 187 & 2 & 540 & 16 \\
\hline Aizawl West & 112 & 9 & 54 & 0 & 50 & 1 & 44 & 2 & 20 & 1 & 17 & 0 & 0 & 0 & 297 & 13 \\
\hline Lunglei & 0 & 0 & 47 & 2 & 38 & 1 & 6 & 1 & 7 & 0 & 9 & 0 & 195 & 0 & 302 & 4 \\
\hline Saiha & 9 & 0 & 10 & 0 & 2 & 0 & 0 & 0 & 0 & 0 & 0 & 0 & 0 & 0 & 21 & 0 \\
\hline Champhai & 20 & 2 & 26 & 0 & 4 & 0 & 0 & 0 & 41 & 0 & 6 & 0 & 0 & 0 & 97 & 2 \\
\hline Kolasib & 6 & 0 & 0 & 0 & 0 & 0 & 0 & 0 & 0 & 0 & 0 & 0 & 0 & 0 & 6 & 0 \\
\hline Serchhip & 4 & 0 & 3 & 0 & 1 & 0 & 2 & 0 & 12 & 0 & 8 & 0 & 0 & 0 & 30 & 0 \\
\hline Mamit & 3 & 0 & 7 & 0 & 0 & 0 & 0 & 0 & 0 & 0 & 0 & 0 & 1 & 1 & 11 & 1 \\
\hline Lawngtlai & 0 & 0 & 0 & 0 & 3 & 0 & 2 & 1 & 3 & 0 & 0 & 0 & 16 & 0 & 24 & 1 \\
\hline State Referral Hospital & 0 & 0 & 0 & 0 & 0 & 0 & 62 & 1 & 0 & 0 & 0 & 0 & 0 & 0 & 62 & 1 \\
\hline Total & 252 & 16 & 175 & 4 & 183 & 4 & 150 & 8 & 90 & 1 & 141 & 1 & 399 & 3 & 1390 & 38 \\
\hline
\end{tabular}




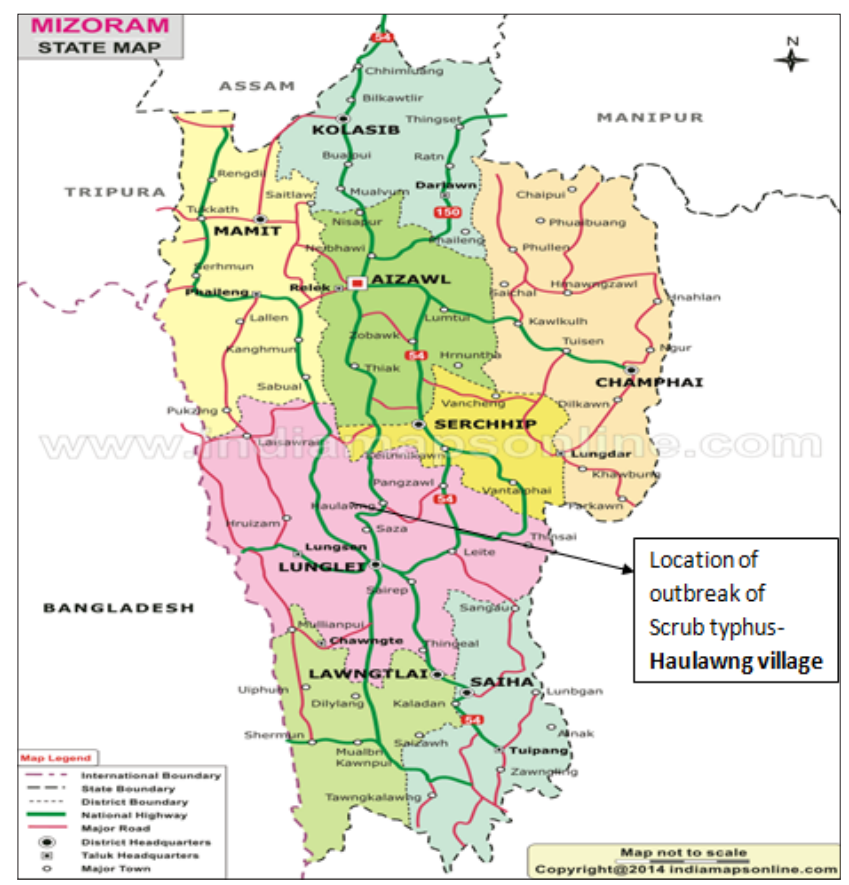

Figure I.Map showing location of outbreak of Scrub typhus

\section{Area Visited}

Following areas of Lunglei district were visited with IDSP and state health officials and selected for the studies:

Haulawng Village: Haulawng is a village panchayat located in the Lunglei district of Mizoram state,India. The latitude 23.051506 and longitude 92.7705136 are the geo coordinate of the Haulawng. It is located $20 \mathrm{KM}$ towards North from District headquarters Lunglei. $21 \mathrm{KM}$ from Lunglei. 88 KM from State capital Aizawl. According to 2011 census, Haulawng Village Total population is 2227 and number of houses are 456.

Zotui Village: Zotui is a Village in Lunglei Block in Lunglei District of Mizoram State, India. It is located $15 \mathrm{KM}$ towards North from District headquarters Lunglei. $96 \mathrm{KM}$ from State capital Aizawl. Total population is 534 and number of houses are 119.

\section{Entomological Survey}

Retrieval of Rodent: Retrieval of rodents were done using live traps. For laying of traps, selection of area was done carefully. Traps were laid in domestic and peri-domestic areas in the evening where there were no cats and dogs as most of the houses in the villages had cats and dogs. Traps were baited with local eatables. The laid traps were collected in the next morning. The positive traps for rodents were brought to the laboratory of Haulawng PHC for further processing.

Processing of rodents in the laboratory: Rodents retrieved were anaesthetized with chloroform and identified after recording their different morphological characteristics. The ectoparasites including chigger (larval) mites were collected by combing the rodent against the fur over a white enamel tray. The snout, ears, limbs and axillary regions of individual animals were combed and the ectoparasites were preserved in 70 per cent alcohol until they were mounted on slides. Rodent blood was drawn, pooled serum was separated and kept for further testing Weil Felix reaction at Zoonosis division, NCDC, Delhi.

Dissection of Rodents: Ear pinna of rodents were dissected and kept in $70 \%$ alcohol for identification. Dissection of the body was also done and organ impression smears of rodent heart, lungs, liver and spleen were made, fixed and kept for further investigation and identification of Rickettsia like bodies.

Mounting and Identification of Ectoparasites: Mites were mounted in Hoyer's medium, examined under microscope and identified up to species level, following standard taxonomical keys. ${ }^{4}$ Other ectoparasites collected were also mounted in Hoyer's medium, examined under microscope and identified using the standard method described earlier by Kaushal et al. ${ }^{5}$

\section{Results and Discussion}

A total of 45 traps were placed in four localities in two areas viz., Hall Veng, Mausen Veng, Bungalow area (Haulawng village) and Zotui village over the entire duration of the study. Three (3) rodents were trapped from Haulawng village, giving an overall positivity rate of $6.7 \%$. The details of rodent species according to the location are presented in Table 2.

Table 2.Rodent species according to the location

\begin{tabular}{|c|c|c|c|c|}
\hline Village (locality) & Traps Laid & Trap Positive & Trap Positivity Rate & Rodent Species \\
\hline Haulawng (Hall Veng) & 15 & 02 & 13.3 & Rattus rattus, Tupaia belangeri \\
\hline Zotui & 15 & 0 & 0 & Nil \\
\hline $\begin{array}{c}\text { Haulawng (Mausen Veng and } \\
\text { Bungalow area) }\end{array}$ & 15 & 01 & 6.7 & Rattus rattus \\
\hline Total & 45 & 03 & 6.7 & \\
\hline
\end{tabular}


Table 3.Ectoparasites (mite, flea and lice) retrieved from the trapped rodents

\begin{tabular}{|c|c|c|c|c|c|c|c|}
\hline \multirow{2}{*}{ Place/ Locality } & \multirow{2}{*}{$\begin{array}{l}\text { No of } \\
\text { Traps } \\
\text { laid }\end{array}$} & \multirow{2}{*}{$\begin{array}{l}\text { Trap } \\
+ \text { ve }\end{array}$} & \multicolumn{2}{|c|}{ Rodent Species } & \multicolumn{3}{|c|}{ Ectoparasites Collected } \\
\hline & & & $\begin{array}{l}\text { Rattus } \\
\text { rattus }\end{array}$ & $\begin{array}{l}\text { Tupaia } \\
\text { Belangeri }\end{array}$ & Mites & Lice & Fleas \\
\hline Haulawng (Hall veng) & 15 & 02 & 01 & 01 & $\begin{array}{c}7 \\
\text { (Leptotrombidium } \\
\text { deliense) }\end{array}$ & & $\begin{array}{c}04 \\
\text { (Xenopsylla } \\
\text { astia) }\end{array}$ \\
\hline Zotui & 15 & - & - & - & - & - & - \\
\hline $\begin{array}{c}\text { Haulawng (Mausenveng } \\
\text { \& Bungalow area) }\end{array}$ & 15 & 01 & 01 & - & $\begin{array}{c}30 \text { (Leptotrombidium } \\
\text { deliense) }\end{array}$ & 01 & - \\
\hline Total & 45 & 03 & 02 & 01 & 37 & 01 & 04 \\
\hline \multicolumn{8}{|c|}{ Rodent Infestation Rate- 100, Chigger Index-12.33, Flea Index-1.33 } \\
\hline
\end{tabular}

Table 4.Rodent serum samples for agglutination against $\mathbf{0 X}-\mathrm{K}$ antigen in Weil-Felix test

\begin{tabular}{|c|c|c|}
\hline Rodent species & Number tested & Titre for agglutination against OX-K (Scrub typhus) antigen \\
\hline Rattus rattus & 01 & $1: 20$ \\
\hline Tupaia belangeri & 01 & $1: 80$ \\
\hline
\end{tabular}

Ectoparasite Indices: The ectoparasites (mite, flea and lice) retrieved from the trapped rodents are given in the Table 3.

Of all the ectoparasite mites sampled from the rodents, Leptotrombidium deliense was the only mite species found. Total 37 vector larval trombiculide mite chigger (Leptotrombidium deliense) were collected from the rodents giving an overall chigger index (average number of chiggers infesting a single host) as 12.33 which is 17 times above the critical value (i.e index $0.69 /$ rodent). Chigger infestation rate was found to be 18.5

The chigger infestation was found mainly on Rattus rattus. Vector mite infestation was found to be highest amongst the rodents trapped followed by fleas and lice. A total of 4 Xenopsylla astia were also retrieved from these rodents with Flea index 1.33 which is more than critical index (i.e. index 1.0) for plague transmission.

\section{Serological Test Result for Rodent Sample}

A total of 2 serum samples were taken from various rodents species captured alive, processed at Zoonosis division of NCDC, Delhi for detection of Orientia (Scrub typhus) antigen and titres were found as 1:20 for Rattus rattus and 1:80 for Tupaia belangeri by Weil Felix OX-K antigen. Thus the serum collected from Tupaia belangeri was found to be positive with scrub typhus pathogen. Rodent serum samples for agglutination against $\mathrm{OX}-\mathrm{K}$ antigen in Weil-Felix test are given in Table 4. Not much data on rodent and ectoparasite surveillance from Lunglei district of Mizoram was found before. Similar ecological condition like Mizoram, entomological surveillance was done in Himachal Pradesh during the outbreak of scrub typhus in 2003 wherein, chigger index (2.46) and flea index (0.89) was recorded and habitat conducive for harboring/propagation of rodents and mites. ${ }^{6}$ Study was also done in Meghalaya in which a total 68 larval trombiculid mite chigger ( $L$. deliense) was vector of scrub typhus collected from the rodents giving an overall chigger index as 1.80 , which was above the critical index of 0.69 per rodent and chigger infestation rate was $4.8 .^{7}$ Earlier study was also done in Tamil Nadu in which a total of 3 larval trombiculid mite chigger - Leptotrombidium deliense were collected from the rodents giving an overall chigger index as $0.17 .{ }^{1}$ The present study has indicate that there is a definite evidence of high level transmission of scrub typhus as compared with earlier studies in which chigger index is 12.33. It reveals that chigger index is too high for transmission to occur as critical index for transmission of Scrub typhus is 0.69 . Also chigger infestation rate was found to be 18.5 which is too high is for transmission of Scrub typhus to occur. But at the same time studies was done in Thailand and most ectoparasites collected from rodents were chigger mites (88.9\%), with Leptotrombidium deliense (72.1\%) the predominant species of the 400 individual chiggers identified. ${ }^{8}$ This study showed that chigger index is far too high in Thailand than the present study done in Mizoram. Leptotrombidium mites support the transmission of Scrub typhus in the area. Before the onset of transmission season early case detection through regular surveillance and laboratory diagnosis should be strengthened for the proper and early treatment of Scrub typhus cases to prevent morbidity and mortality. Regular health education should be undertaken by the local health officials to the local masses about causation of this disease, vector mites responsible, it's transmission cycle and seasonality, so that they can take the required preventive measures to curtail the transmission. 
People frequently visiting forest areas for their work may be advised to apply locally available repellents on their legs, arms and other exposed body parts to prevent mite bites for the prevention and control of the Scrub typhus. ${ }^{1}$

Also in our study Tupaia belangari (Northern tree shrew) has 1:80 titre for agglutination against OX-K (Scrub typhus) antigen which reveals that the serum was found to be positive for Scrub typhus which could be the first report even though vector of Scrub typhus Leptotrombidium deliense was not present in the tree shrew and although they are in rodent family. The Northern Tree Shrew Tupaia belangeri is endemic to the Indo-Burma Biodiversity Hotspot widely distributed in the tropical deciduous forests of northeastern India (Assam, Meghalaya, Manipur, Mizoram, Nagaland and Sikkim), eastern Nepal, Bangladesh, southeastern China, Indo-china and the Malay Peninsula of the Oriental realms with Yunnan-Kweichow Plateau being its northern limit. Bamboos in the habitat possibly provided the escape sites from predators like snakes, which are common in the habitat of this mammal. ${ }^{9}$ Our finding shows that other than rodents Tupaia belangari (tree shrews) can also be infected with the pathogen of Scrub typhus but transmission to human beings is not known since the vector is not present. Since Scrub typhus is caused by Orientia tsutsugamushi which is a bacteria, various studies also shows that Tupaia belangari can be used to establish bacterial infection models like Staphylococcus aureus, Pseudomonas aeruginosa and Mycobacterium tuberculosis. ${ }^{10}$ Earlier study in 2017 in Mizoram also revealed that the emergence or re-emergence of scrub typhus disease in Mizoram might be associated with the incidence of bamboo flowering in the state in the year 2007-2009 as several sporadic scrub typhus-like illness were claimed to be treated from those years by medical practitioners. The emergence of the disease might be due to rapid increase in rodent population that feeds on nutritious bamboo fruits and flowers. Many rodent population outside the state might migrated to the state due to the availability of food for them. The pathogen responsible for scrub typhus, O.tsutsugamushi might be transported inside the state by the migrating rodents from various potential sites outside the state. ${ }^{11}$

\section{Conclusion}

Ecology of Mizoram highly supports the survival of chigger mites. Cases of Scrub typhus are reported in low socialeconomic group distributed far and wide in many districts of Mizoram having characteristic terrain features supportive of Scrub typhus. High infestation rate of rodents and vector Leptotrombidium mites support the probability of ongoing transmission of Scrub typhus in the area. The present study concluded that regular and continuous rodent and ectoparasite surveillance should be carried out to maintain rodent, flea and mite density below critical level and to prevent from transmission of Scrub typhus.

\section{Acknowledgement}

We are grateful to the Director, NCDC, for providing facilities and giving an opportunity to undertake entomological surveillance in Mizoram. We would also like to thank Dr. Pachuau Lalmalsawma, State Surveillance officer, IDSP, Mizoram, Mr. Lalfakzuala Pautu, State Entomologist, IDSP, Mizoram, Shri Mohd. Muzib, Assistant Research Officer, NCDC, Delhi for the technical assistance provided.

Conflict of Interest: None

\section{References}

1. Samuel PP, Kamarasu K, Govindarajan R, Selvam A, Victor Jerald Leo S, Arunachalam N. Preliminary investigation on the prevalence of scrub typhus vectors in Krishnagiri district, Tamil Nadu, India. J Adv Zool 2017; 38(2): 128132.

2. Sadanandane $C$, Elango A, Kummankottil P, Karthikeyan PA, Agatheswaran S, Jambulingam P. Abundance \& distribution of trombiculid mites \& Orientia tsutsugamushi, the vectors \& pathogen of scrub typhus in rodents \& shrews collected from Puducherry \& Tamil Nadu, India. Indian J Med Res 2016; 144: 893-900.

3. Sayantani C. Nilendu SScrub typhus: An emerging threat. IJD Symposium 2017; 62(5): 478-485.

4. Stan Fernandes SJ, Kulkarni SM. Studies on the Trombiculid Mite Fauna of India. Records of the Zoological Survey of India. Zoological Survey of India, Kolkata 2003; 212: 1-539.

5. Kumar K, Sharma SK, Gill KS, Katyal R, Biswas S, Sohan L. Entomological \& rodent prevalence in Plague suspected area during Sept. 1994 and thereafter. Jap J Med Science \& Bio 1997; 50(3): 97-113.

6. Kumar K, Saxena VK, Thomas TG, Lal S. Outbreak investigation of Scrub typhus in Himachal Pradesh (India). J Com Dis 2004; 36(4): 277-283.

7. Sharma AK. Entomological surveillance for rodent and their ectoparasites in Scrub typhus affected areas of Meghalaya, (India). Journal of Entomology and Zoology Studies 2013; 1(6): 27-29.

8. Wuttikon R, Narupon K, Piyada L, Yutthapong S, Allen LR, Maneerat S et al. Scrub typhus Outbreak in Chonburi Province, Central Thailand, 2013. 2018; 24: 2.

9. Majumder J, Agarwala BK. Notes on the distribution, habitat, and behavior of Northern Tree Shrew Tupaia belangeri (Mammalia: Scandentia: Tupaiidae) in Tripura, India. Journal of Threatened Taxa 2015; 7(1): 6841-6842.

10. Xiao J, Liu R, Chen CS. Tree shrew (Tupaia belangari) as a novel laboratory disease animal model. Zoological Research 2017; 38(3): 127-137.

11. Lalmalsawma P, Pautu L, Lalremsiama N. Scenario of Scrub typhus disease in Mizoram, North-East India. International Journal of Current Advance Research 2017; 6(10): 6341-6344. 